\title{
SOCIAL DISTANCING, AUTONOMOUS VEHICLES' UNEXPECTED SUPPORTER - HOW COVID-19 HAS CHANGED FUTURE MOBILITY BEHAVIOUR AND PERCEPTION IN EUROPE
}

\author{
Christina F. Edye, Zeppelin University, Germany
}

dx.doi.org/10.18374/JABE-20-4.4

\begin{abstract}
The future concept of autonomous vehicles is based on assumptions, that the mobility world moves further towards sharing economies, such as car-sharing business and car-pooling opportunities, and away from private vehicle ownership. But the pandemic resulted in the opposite. People are avoiding strangers through social distancing, using fewer public transport options and instead an increasing number of private vehicles. If fully autonomous vehicles are for individual use only, and correct hygiene measures are put into place, the technology could provide a good transport alternative to current options. On the assumption, that theoretically the acceptance of self-driving cars should rise due to social distancing possibilities, this study was created. Focusing on perceived ease of use, perceived usefulness and social distancing attitude, the hypothetical use of robo-taxis during this pandemic is assessed. Pre COVID-19, previous studies revealed that acceptance of the technology was declining. With a changing mobility attitude and perception, could this be the time to market autonomous vehicles as a useful alternative to public transport and grow its acceptance? Using the Technology Acceptance Model, this paper asses the opinion of 1593 Europeans towards robo-taxis, self-driving cars as a whole, and the changing mobility behaviour as a result of COVID-19. The results show that $47.5 \%$ of participants, an increase of $5.3 \%$ compared to pre-pandemic times, would use robo-taxis during the pandemic and $48.6 \%$ would like to own a self-driving vehicle if they were available. While the pandemic has resulted in a decline of mobility movement across the world, it opened up the opportunity of rethinking the future mobility world.
\end{abstract}

Keywords: Autonomous vehicles, pandemic, acceptance, mobility behaviour, change 